\title{
Kinetic Study of the Nitrogen Removal Rate from Molten Steel (Normal Steel and 17 mass\%Cr Steel) under CO Boiling or Argon Gas Injection
}

\author{
Takeo INOMOTO, ${ }^{1) *}$ Shin-ya KITAMURA ${ }^{2)}$ and Masataka YANO ${ }^{3)}$ \\ 1) Process Research Laboratories Nippon Steel \& Sumitomo Metal Corporation, 16-1 Sunayama, Kamisu-shi, Ibaraki, 314- \\ 0255 Japan. \\ 2) Formerly Process Technology Research Laboratories Nippon Steel Corporation. Now at Tohoku University, 2-1 Katahira, \\ Aoba-ku, Sendai-shi, Miyagi, 987-8573 Japan. \\ 3) Formerly Process Technology Research Laboratories Nippon Steel Corporation. Professor Emeritus, Aichi University of \\ Technology. Now at 104 Nakagou-aza, Ushikawa-chou, Toyohashi-shi, Aichi, 440-0016 Japan.
}

(Received on September 10, 2014; accepted on May 18, 2015)

\begin{abstract}
A nitrogen removal experiment was carried out under reduced pressure using a 600-kg-scale induction furnace. Using normal and 17 mass $\% \mathrm{Cr}$ steel, two methods to promote the reaction were selected, i.e., expansion of the reaction area with $\mathrm{CO}$ boiling and reduction of surface active elements, with the aim of promoting the chemical reaction at the metal-gas interface. Kinetic results indicate that surface active elements act on the whole experimental condition, and the rate determination step is predicted to be a chemical reaction at the gas-metal interface. Applying the chemical reaction equation obtained by previous research on high-chromium steel, the nitrogen removal rate can be explained using the same estimation method. The results obtained in the present study indicate the importance of development of an effective method to increase the gas-metal surface area.
\end{abstract}

KEY WORDS: steelmaking; reaction rate; nitrogen; vacuum degasser; CO boiling; gas injection.

\section{Introduction}

The study of the chemical reaction rate at the gas-metal interface has seen much progress in the last few decades. Surface active elements, such as sulfur and oxygen, significantly affect the metal-gas interface by reducing the surface reaction rate of nitrogen. Ban-ya et al. investigated this phenomenon by performing 500 -g-scale laboratory tests using the argon blowing method under normal pressure. ${ }^{1)}$ Harashima et al. examined this effect in the high-purity range of steel using a $12-\mathrm{kg}$ vacuum induction furnace. ${ }^{2)}$ In addition, the effect of surface active elements in highchromium steel has been reported by Kiyose et al. ${ }^{3)}$ These studies quantitatively gave the chemical reaction rate coefficient because the equation includes the adsorption parameters of sulfur and oxygen. Takahashi et al. carried out experiments to estimate the nitrogen removal reaction rate through argon bubbles under normal pressure, and nitrogen showed a similar effect to surface active elements, not only at the surface but also at the inner surface of the injected argon bubbles. ${ }^{4,5)}$ In addition, the removal rate of nitrogen with argon injection under reduced pressure has been investigated. ${ }^{6,7)}$ According to the results of these studies, the interfacial area and mass transfer rate significantly increase

\footnotetext{
* Corresponding author: E-mail: inomoto.4m3.takeo@jp.nssmc.com DOI: http://dx.doi.org/10.2355/isijinternational.ISIJINT-2014-610
}

under reduced pressure because of bubble rupture accompanying sharp volume expansion near the metal surface. The surface active elements rapidly adhere to the interface and interfere with nitrogen removal at the gas-metal interface, and this phenomenon occurs under both reduced pressure and normal pressure conditions. In addition, the reaction rate is enhanced by inducing a drastic reduction in the amounts of sulfur and oxygen using the powder blowing effect. ${ }^{9)}$

Reduction in nitrogen content through $\mathrm{CO}$ boiling accompanying decarburization treatment is a well-known phenomenon, and it has been applied to factory-scale treatment in normal steel ${ }^{10)}$ and stainless steel ${ }^{11)}$ production. Recently, a numerical model for the nitrogen removal rate with $\mathrm{CO}$ boiling has been developed for the RH process (normal steel) ${ }^{12}$ ) and the VOD process (stainless steel). ${ }^{13)}$

The interruption effect of the surface active elements is defined by the adsorption coefficients of oxygen and sulfur $\left(\kappa_{\mathrm{O}}\right.$ and $\left.\kappa_{\mathrm{S}}\right)$. Because $\kappa_{\mathrm{O}}$ is much higher than $\kappa_{\mathrm{S}},{ }^{1-3)}$ reduction in oxygen activity is very effective in promoting interfacial reaction.

Therefore, during the vacuum treatment of killed steel, which has low oxygen activity, the chemical reaction rate at the gas-metal interface can be increased. However, $\mathrm{CO}$ boiling, which results from the reaction between dissolved carbon and oxygen in the metal, increases the gas-metal interfacial area and promotes mass transfer in the metal. However, it is not possible to generate $\mathrm{CO}$ boiling in killed 
steel. Therefore, for nitrogen reduction treatment, it is crucial to choose an effective killing method or $\mathrm{CO}$ boiling method. Furthermore, the chromium content in the molten steel significantly affects the activity of several elements, but consistent kinetic study of the nitrogen removal rate in both normal and stainless steel is insufficient.

In this study, based on the experimental results obtained using a 600-kg-scale vacuum induction furnace with nor$\mathrm{mal}^{14)}$ and high-chromium steel, ${ }^{15)}$ kinetic evaluation of nitrogen removal is presented. The effects of the chromium content and the surface active elements when using the killing method and applying the $\mathrm{CO}$ boiling method are taken into consideration.

\section{Experimental Conditions}

In the experiment, $600 \mathrm{~kg}$ of steel (low-alloy steel or steel mixed with metallic chromium) was melted in an argonsealed induction furnace. The molten steel was then poured into a vacuum induction furnace $(50 \mathrm{~Hz})$, and the initial temperature was controlled by the induction current. Then, the initial composition was controlled by alloying under an argon atmosphere $(20-50 \mathrm{kPa})$.

Experiments with $\mathrm{CO}$ boiling using normal and 17 mass\% $\mathrm{Cr}$ steel were carried out under vacuum degassing conditions. During the treatment, iron ore sand $(<2 \mathrm{~mm}$, basic hematite) was periodically added to maintain the desired $\mathrm{CO}$ boiling rate (100-500 g/addition, 2 to 6 min intervals, with camera monitoring). In this experiment, the iron ore addition rate was controlled to avoid metal flooding by interior bubbles, and there was no rising up of the metal surface. Hence, metal-gas interface expansion is considered to be the result of the rupture of bubbles at the surface and metal splashing.

With the aim of reducing the adsorption effect by oxygen, experiments using Al-killed steel were carried out with 0.04- 0.1 mass $\%$ aluminum content, and the oxygen activity measured with a $\mathrm{ZrO}_{2}-\mathrm{MgO}$-type sensor was $<5$ ppm at 1 mass \% standard in pure iron.

The experimental gas-phase pressure was usually 13-26 $\mathrm{Pa}$ or lower. However, in the case of $\mathrm{CO}$ boiling or inevitable weak sealing, the measured pressure sometimes changed but was $<130 \mathrm{~Pa}$. In an experiment such as this, it is difficult to maintain the nitrogen partial pressure in the gas phase, which is essential to determine the reaction rate. Instead of maintaining nitrogen partial pressure, the reaction rate was measured in a sufficiently high nitrogen content range so the fluctuation of nitrogen partial pressure did not significantly affect the estimated reaction rate value.

The experiment in the present study was carried out using normal and 17 mass \% Cr steel, and the equilibrium nitrogen content and nitrogen partial pressure can be expressed by the following equations:

$$
\begin{gathered}
1 / 2 \mathrm{~N}_{2} \rightarrow \underline{\mathrm{N}} \ldots \ldots \\
\mathrm{K}_{1}=\mathrm{a}_{\mathrm{N}} / \mathrm{P}_{\mathrm{N}_{2}}{ }^{1 / 2} \ldots . \\
{[\mathrm{N}]_{\mathrm{e}}=\mathrm{K}_{1} \cdot \mathrm{P}_{\mathrm{N}_{2}}{ }^{1 / 2} / \mathrm{f}_{\mathrm{N}}}
\end{gathered}
$$

where $\mathrm{K}_{1}$ is the equilibrium constant (at $1873 \mathrm{~K}$ ), $\mathrm{P}_{\mathrm{N}_{2}}$ is the nitrogen pressure at the interface $(\mathrm{Pa}), \mathrm{a}_{\mathrm{N}}$ is the equilibrium nitrogen activity $(-),[\mathrm{N}] \mathrm{e}$ is the equilibrium nitrogen content (mass $\%$ ), and $\mathrm{f}_{\mathrm{N}}$ is activity coefficient of nitrogen.

Using the thermodynamic data in Ref. 16), the relationship between atmospheric nitrogen pressure and equilibrium nitrogen content is shown in Fig. 1. The chromium content in the metal reduces the nitrogen activity coefficient $\left(f_{N}\right)$. Thus, under the same atmospheric conditions, the equilibrium nitrogen content of 17 mass $\% \mathrm{Cr}$ steel is much higher value than that of normal steel. Therefore, in the present study, the nitrogen content in the 17 mass $\% \mathrm{Cr}$ steel experiment was measured in a higher range than the nitrogen content range in a normal steel experiment.

\section{Results and Discussion}

\subsection{Nitrogen Removal Rate with CO Boiling}

Figure 2 shows the change in $[\mathrm{N}]$ during the normal steel experiments. At high-carbon-content $(\square)$, a high reaction rate was observed because a high dissolved oxygen content cannot be maintained. However, in the case of sulfur addition $(\boldsymbol{\Delta})$, the reaction rate was the lowest. This result confirms that surface active elements have an obstructive effect, even under violent $\mathrm{CO}$ boiling conditions. In this figure, $\mathrm{Fco}(\mathrm{Nl} / \mathrm{min})$ indicates the average $\mathrm{CO}$ gas generation rate, which is calculated from the carbon content change in each run.

Figure 3 shows the experimental results obtained under several $\mathrm{CO}$ boiling conditions using 17 mass $\% \mathrm{Cr}$ steel. In this experiment, the $\mathrm{CO}$ gas generation rate $\left(\mathrm{F}_{\mathrm{CO}}\right)$ was

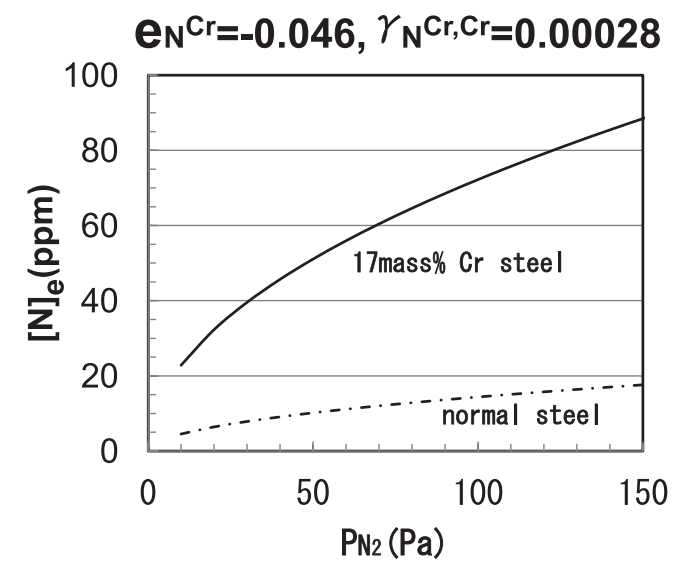

Fig. 1. Equilibrium nitrogen content in the molten steel (1 $873 \mathrm{~K})$.
Table 1. Experimental conditions.

\begin{tabular}{ll}
\hline Crucible & $:$ MgO, inner diameter $=380 \mathrm{~mm}$ \\
Temperature & $: 1843-1873 \mathrm{~K}$ \\
Metal weight & $: 600 \mathrm{~kg} / \mathrm{ch}$ \\
Pressure & $:<130 \mathrm{~Pa}$ (normal 13-26 Pa) \\
CO boiling experiment & $: 0.1-0.3$ mass $\%$ \\
Initial [C] & $:$ iron ore sand (periodic addition) \\
Oxygen supply & \\
Al-killed steel & $: 0.04-0.10$ mass $\%$ ao $<5$ ppm \\
[Al] & $: 0.0-3.4 \mathrm{Nl} / \mathrm{min}$ \\
Bottom Ar injection &
\end{tabular}


Table 2. Composition of the metal during each experiment (mass\%).

\begin{tabular}{ccccc}
\hline & \multicolumn{2}{c}{ CO boiling experiment } & \multicolumn{2}{c}{ Al-killed experiment } \\
\cline { 2 - 5 } & normal steel & 17 mass $\%$ Cr steel & normal steel & 17 mass\%Cr steel \\
\hline$[\mathrm{C}]$ & $0.30-0.05$ & $0.30-0.05$ & $<0.01$ & $<0.01$ \\
{$[\mathrm{Si}]$} & $<0.05$ & $<0.05$ & $<0.05$ & $<0.05$ \\
{$[\mathrm{Mn}]$} & $<0.1$ & $<0.1$ & $<0.1$ & $<0.1$ \\
{$[\mathrm{P}]$} & $<0.02$ & $<0.02$ & $<0.02$ & $<0.02$ \\
{$[\mathrm{~S}]$} & $0.004-0.006 \%$ & $0.004-0.006$ & $0.004-0.006$ & $0.004-0.006$ \\
{$[\mathrm{Al}]$} & $<0.01$ & $<0.01$ & $0.040-0.100$ & $0.040-0.100$ \\
{$[\mathrm{Cr}]$} & $<0.1$ & $<0.1$ & $<0.1$ & $16-18$ \\
{$[\mathrm{t} . \mathrm{O}]$} & $0.001-0.020$ & $0.001-0.020$ & $<0.002$ & $16-18$ \\
{$[\mathrm{~N}]$} & $0.012-0.003$ & $0.012-0.003$ & $0.012-0.004$ & $0.055-0.016$ \\
\hline
\end{tabular}

*except high [S] condition

\section{normal steel ,Fco=34-41( $\mathrm{NI} / \mathrm{min})$}

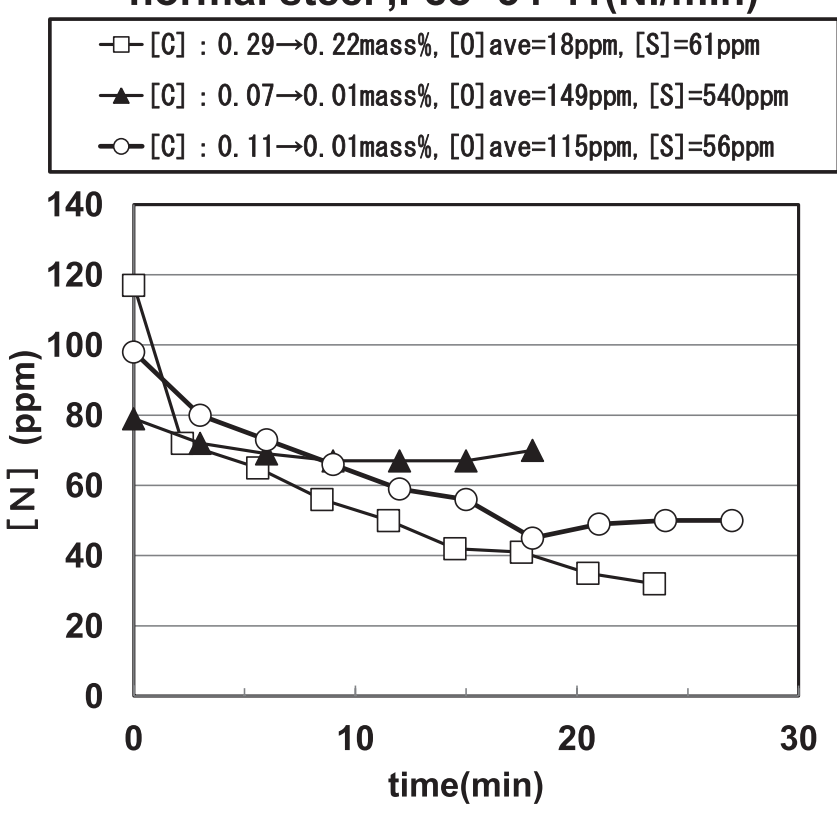

Fig. 2. Change in $[\mathrm{N}]$ with $\mathrm{CO}$ boiling (normal steel).

controlled in each run by changing the iron ore sand supply condition.

Generally, the nitrogen removal reaction rate is classified by three types of determination steps: mass transfer of nitrogen in the metal (first-order reaction), chemical reaction at the interface (second-order reaction), and mass transfer of $\mathrm{N}_{2}$ in the gas (second-order reaction).

During the degassing treatment, CO boiling was continuously observed on the whole metal surface, so nitrogen removal phenomena through gas bubbles must be considered when estimating the reaction rate. Takahashi et $a l^{5)}$ studied the nitrogen removal rate in injected argon bubbles using normal steel under normal pressure. Their results showed that the reaction rate is controlled by the chemical reaction at the bubble surface and mass transfer in the metal. The chemical reaction rate was almost constant in a low oxygen content range $(<100 \mathrm{ppm})$ but it decreased with increasing oxygen content in a high oxygen content

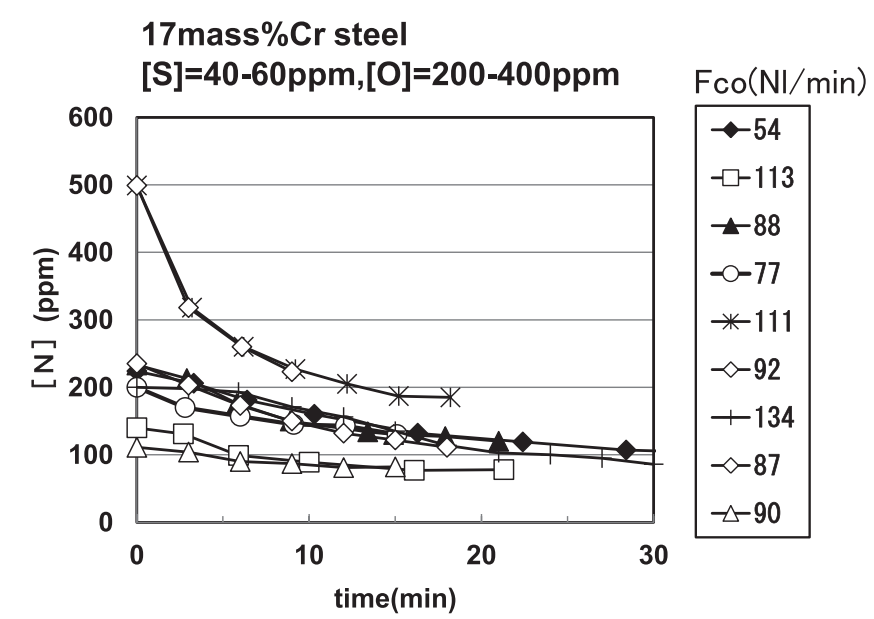

Fig. 3. Change in $[\mathrm{N}]$ with $\mathrm{CO}$ boiling (17 mass $\% \mathrm{Cr}$ steel).

range $(>100 \mathrm{ppm})$. Thoms et al. $^{6)}$ measured the nitrogen removal rate with argon bubbling under reduced pressure (270-46 $000 \mathrm{~Pa})$, and the results showed that the reaction rate is determined only by the chemical reaction step even under low surface, active element content conditions (oxygen 5-6 ppm, sulfur $17 \mathrm{ppm}$ ). These results indicate that it is necessary to consider both mass transfer in the metal and chemical reaction at the interface to estimate the total reaction rate by nitrogen absorption into the bubble.

The total reaction rate is mainly determined by the lowest reaction step. The present experiments were carried out with high mixing force by the induction coil current and strong $\mathrm{CO}$ gas boiling under reduced pressure, so the reaction rate is assumed to be the secondary reaction rate by the chemical reaction rate.

Considering the physical properties of normal and 17 mass $\% \mathrm{Cr}$ steel, the differences in density, surface tension, and mass transfer coefficient in the metals are less than $5 \% .{ }^{17,18)}$ Thus, except for the effect of chromium in the activity of solved elements, the reaction rate can be estimated in the same way.

Assuming that the reaction is above ground, the overall reaction coefficient $\mathrm{k}_{\mathrm{N}}{ }^{\prime}$ obtained by Eq. (4) is plotted against the $\mathrm{CO}$ gas evolution rate in Fig. 4. 


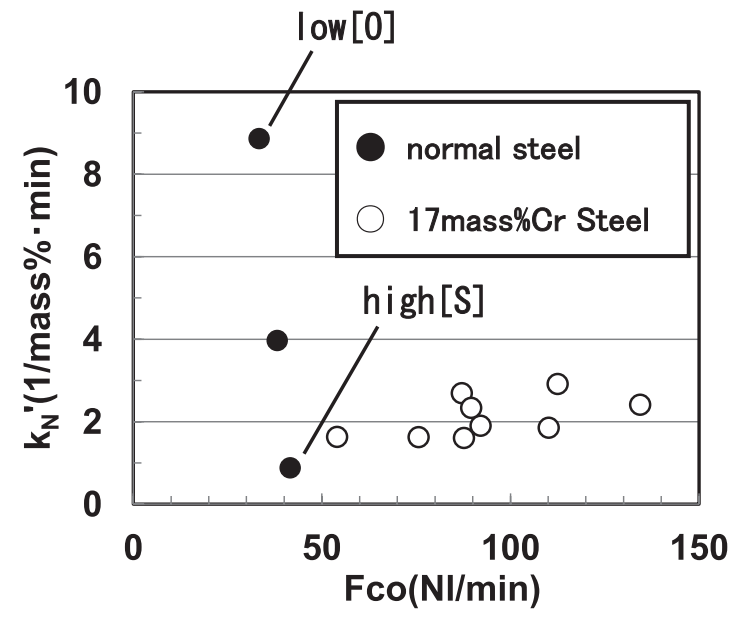

Fig. 4. Overall reaction rate coefficient with $\mathrm{CO}$ boiling (secondary reaction).

$$
-\mathrm{d}[\mathrm{N}] / \mathrm{dt}=\mathrm{k}_{\mathrm{N}^{\prime}}\left([\mathrm{N}]^{2}-[\mathrm{N}]_{\mathrm{e}}^{2}\right)
$$

where $[\mathrm{N}]$ is the nitrogen content in the metal (mass\%), $[\mathrm{N}]_{\mathrm{e}}$ is the equilibrium nitrogen content in the metal (mass\%), which is approximately zero, and $\mathrm{k}_{\mathrm{N}}{ }^{\prime}$ is the overall reaction coefficient (second order) $(1 / \mathrm{mass} \% \cdot \mathrm{min})$.

As shown in Fig. 4, the overall reaction rate is strongly affected by the adsorption effect and activity shift according to the chromium content. If only considering this figure, no definite trend can be observed.

Kiyose et al. ${ }^{3)}$ investigated the effect of chromium content in previous experimental work. Their experiment was carried out without $\mathrm{CO}$ boiling or argon gas injection, and the reaction rate was given by the second-order reaction rate equation. The following chemical reaction rate coefficient was proposed:

$$
\mathrm{k}_{\mathrm{r}}=0.057 \mathrm{f}_{\mathrm{N}}^{1.2} /\left(1+161 \mathrm{a}_{\mathrm{O}}+54.5 \mathrm{a}_{\mathrm{S}}\right)^{2}
$$

where $\mathrm{k}_{\mathrm{r}}$ is the chemical reaction coefficient at the metal surface $(\mathrm{m} / \mathrm{mass} \% \cdot \mathrm{s}), \mathrm{f}_{\mathrm{N}}$ is the activity coefficient of the nitrogen in the metal, $a_{O}$ is activity of oxygen in the metal, and $a_{\mathrm{S}}$ is the activity of sulfur in the metal.

As described above, the nitrogen removal rate is controlled by the chemical reaction at the interface. Eq. (4) can be expressed by the following equation:

$$
-\mathrm{d}[\mathrm{N}] / \mathrm{dt}=\mathrm{k}_{\mathrm{r}} \mathrm{V} /\left(60 \mathrm{~A}_{\mathrm{act}}\right) \times\left([\mathrm{N}]^{2}-[\mathrm{N}]_{\mathrm{e}}^{2}\right)
$$

where $A_{\text {act }}$ is the reaction site area activated by CO boiling $\left(\mathrm{m}^{2}\right)$ and $\mathrm{V}$ is the volume of the metal $\left(0.086 \mathrm{~m}^{3}\right)$.

From Eqs. (4) and (6), the reaction site area can be calculated by Eq. (7), and the relationship between $A_{\text {act }}$ and Fco is shown in Fig. 5.

$$
\mathrm{A}_{\mathrm{act}}=\left(\mathrm{k}_{\mathrm{N}^{\prime}} \mathrm{V}\right) /\left(60 \mathrm{k}_{\mathrm{r}}\right)
$$

As shown in Fig. 5, there is a linear relationship between Fco and $A_{\text {act. }}$. In this figure, the solid square ( $\left.\mathbf{a}\right)$ means the metal surface area without $\mathrm{CO}$ boiling $\left(0.11 \mathrm{~m}^{2}\right)$. Thus, according to the above estimation, the reaction area by $\mathrm{CO}$ boiling increased to around 10 times the initial surface area.

The physical phenomenon of $\mathrm{CO}$ boiling under low pressure is important. However, quantitative estimation of this interfacial phenomenon is quite difficult because there are

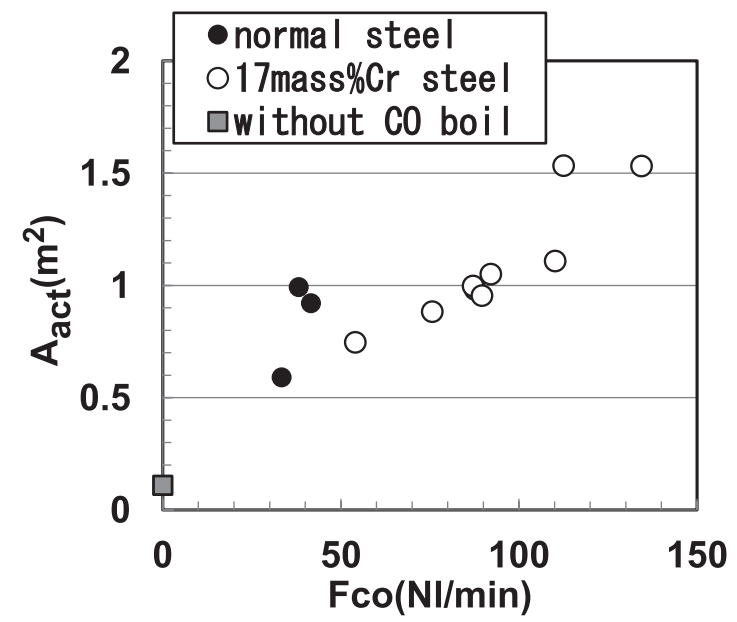

Fig. 5. Evaluated reaction area by $\mathrm{CO}$ boiling.

several unknown factors, such as the pressure of the bubble at the bursting position, the depth of the bubble generation, and the lifetime of the generated bubble.

Therefore, instead of a precise calculation, a rough estimation of the surface expansion phenomenon is described as follows. By observing the bubble bursting phenomenon at the metal surface, the diameter of the bubble at the surface is around $50 \mathrm{~mm}$. Assuming that the bubble bursting pressure at the surface is $130 \mathrm{~Pa}$ and the bubble generation depth is $100 \mathrm{~mm}(7000 \mathrm{~Pa})$, the initial diameter of a bubble that expands to $50 \mathrm{~mm}$ at the surface is estimated to be $13 \mathrm{~mm}$. Thus, the expanded gas-metal surface area by $\mathrm{CO}$ boiling caused by $\mathrm{CO}$ bubbles at the shallow position is less than 50 $\mathrm{mm}$ in diameter. In addition, a large amount of metal splash is generated by $\mathrm{CO}$ boiling, so the surface expansion effect of the splash is also significant.

\subsection{Nitrogen Removal Rate in Al-Killed Steel}

The experimental results of the change in nitrogen content are shown in Figs. 6 and 7. In the case of no argon gas injection, the nitrogen reduction rate cannot be ignored. To estimate the nitrogen removal rate in this experiment, argon injection increases not only the gas-metal interface area but also the mixing energy that promotes nitrogen mass transfer in the metal. Therefore, if the mass transfer rate in the metal is not sufficiently high, reaction rate estimation becomes a difficult problem.

Based on the experimental conditions and initial nitrogen content, the reaction rate of the chemical reaction step can be calculated by Eq. (6). The experimental result without argon injection $\left(\mathrm{A}_{\mathrm{act}}=0.11\right)$ and the calculated result are shown in Fig. 8, and there is good agreement between the experimental result and the calculated value. This result shows that under this experimental condition, the mixing energy by induced current is sufficiently high and the reaction rate determining step can be estimated by chemical reaction at the gas-metal interface. In addition, this result indicates the validity of the assumption described in Section 3.1 that the reaction rate of the CO boiling test with high oxygen content of mass transfer rate is sufficiently high and the overall reaction rate can be estimated by Eq. (4).

Figure 9 shows the relationship between the argon injection rate and $\mathrm{k}_{\mathrm{N}^{\prime}}$, determined by Eq. (4). The reaction rate 


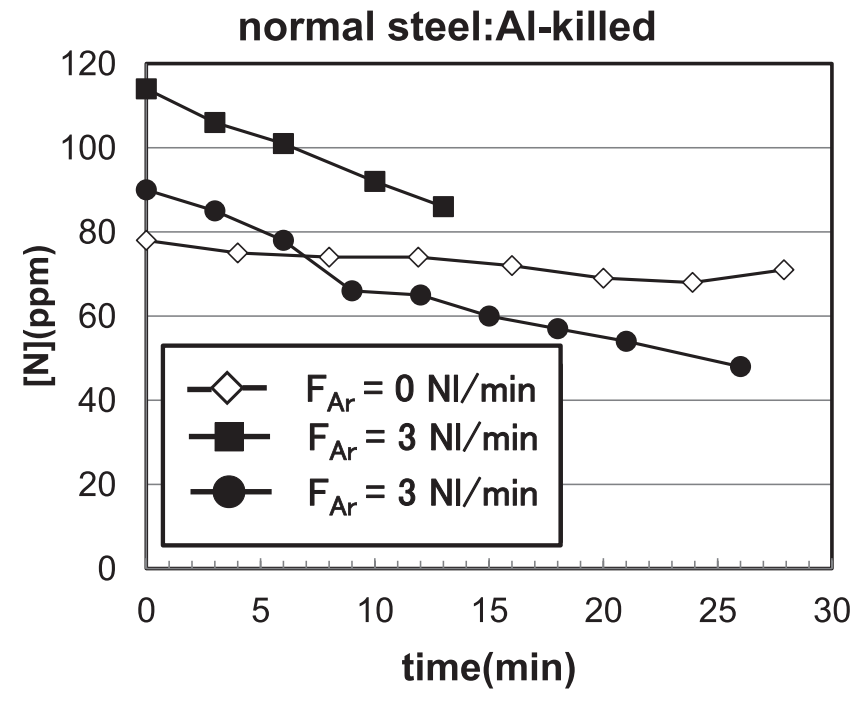

Fig. 6. Change in $[\mathrm{N}]$ of Al-killed steel (normal steel).

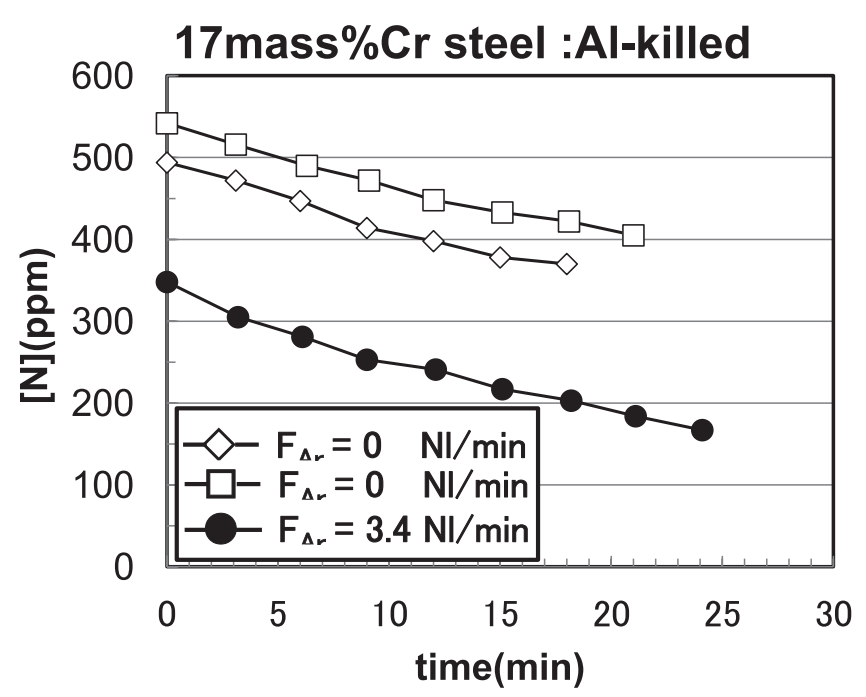

Fig. 7. Change in $[\mathrm{N}]$ of Al-killed steel $(17$ mass $\% \mathrm{Cr}$ steel).

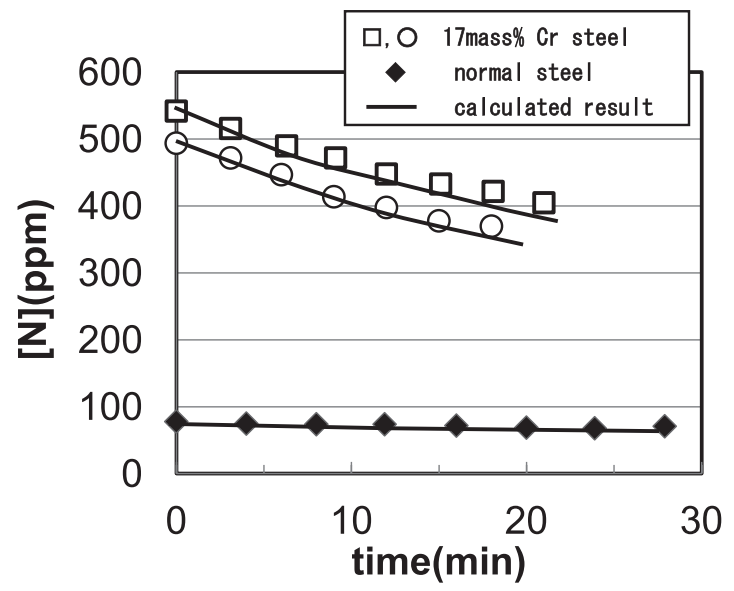

Fig. 8. Change in nitrogen content of Al-killed steel without Ar bubbling.

obtained is nearly the same as that in the $\mathrm{CO}$ boiling experiment, and the reaction rate value is higher for normal steel than that for 17 mass $\% \mathrm{Cr}$ steel.

Figure 10 shows a plot of the $\mathrm{A}_{\text {act }}$ value calculated from

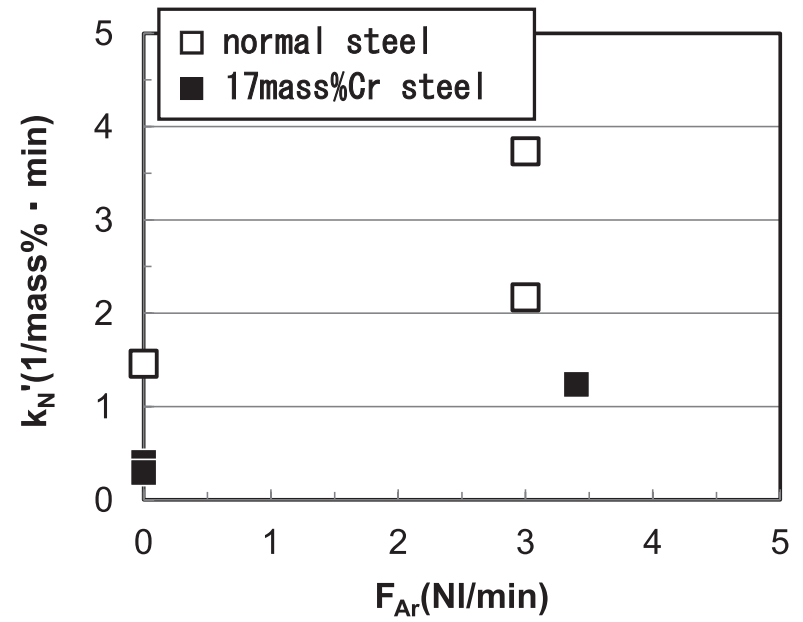

Fig. 9. Overall reaction rate coefficient of Al-killed steel (secondary reaction).

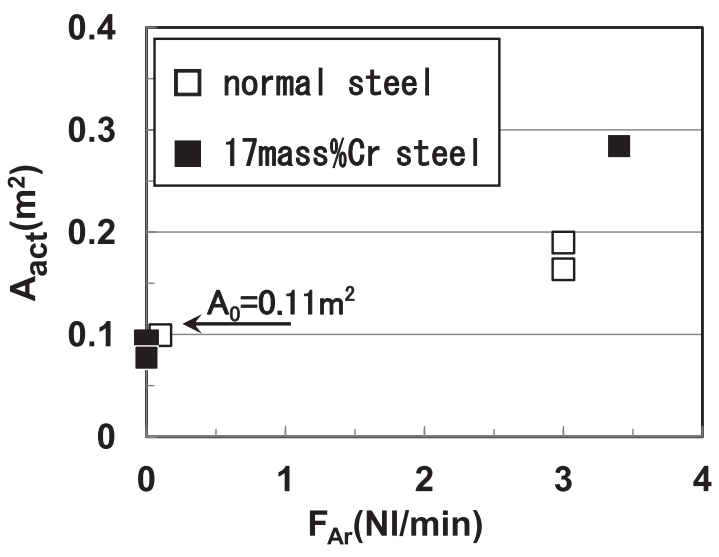

Fig. 10. Evaluated reaction area by argon bubbling.

Eq. (7). In this case, the calculated $A_{\text {act }}$ is much smaller than the value shown in Fig. 5 (CO boiling condition). Under these conditions, it was difficult to increase the bottom argon gas injection rate to more than that of the present runs because the increase in metal splashing prevents stable operation.

As described in Section 3.1, the rate of gas flow passing through the metal surface with $\mathrm{CO}$ boiling can be increased to more than $100 \mathrm{Nl} / \mathrm{min}$ by small bubble generation at a shallow depth in the whole metal surface. However, the argon injection method cannot impose the same gas-metal interfacial condition. An efficient method for increasing the gas-metal interfacial area for killed steel is required, and technical development of this field is important.

\section{Conclusion}

The rate of nitrogen removal from molten metal (normal steel and 17 mass\% Cr steel) was experimentally investigated using two reaction promotion methods with a $600-\mathrm{kg}$ scale vacuum induction furnace.

\subsection{Reaction Area Expansion by CO Boiling}

- The nitrogen removal rate is significantly influenced by surface active elements, and the effect can be 
quantitatively explained by calculating the adsorption effect and the chromium content up to stainless steel grade.

- Evaluation of CO gas formation and the metal surface area showed that the reaction area is 10 times the metal surface area, which is considered to be the main reason for the increased reaction rate.

\subsection{Reduction in the Interference Effect by Al Killing}

- Argon gas injection can significantly promote the reaction rate in both normal and high-chromium steel.

- Reduction in the surface active elements can promote the reaction rate to the same order as $\mathrm{CO}$ boiling. However, it is difficult to obtain effective expansion of the interfacial area using argon injection. Thus, technical development to resolve this issue is important.

Thus, the results of this study might be useful for evaluating the optimum nitrogen removal conditions in several steelmaking processes.

\section{Nomenclature}

$\kappa_{\mathrm{O}}$ : adsorption coefficient of oxygen $(-)$

$\kappa_{\mathrm{S}}$ : adsorption coefficient of sulfur $(-)$

[N]: nitrogen content in the metal (mass\%) (ppm)

$[\mathrm{N}]_{\mathrm{e}}$ : equilibrium nitrogen content in the metal (mass\%) (ppm)

$\mathrm{k}_{\mathrm{N}}$ : overall reaction coefficient (second order) (1/mass $\%$. $\min )$

$\mathrm{t}$ : time (min)

$\mathrm{k}_{\mathrm{r}}$ : chemical reaction coefficient at the metal surface $(\mathrm{m} / \mathrm{mass} \% \cdot \mathrm{s})$

$\mathrm{f}_{\mathrm{N}}$ : activity coefficient of the nitrogen in the metal (-)
$\mathrm{a}_{\mathrm{S}}$ : activity of sulfur in the metal $(-)$

$\mathrm{a}_{\mathrm{O}}$ : activity of oxygen in the metal $(-)$

$\mathrm{A}_{\text {act }}$ : reaction area according to the gas-metal interface $\left(\mathrm{m}^{2}\right)$

$\mathrm{V}$ : volume of the metal $\left(\mathrm{m}^{3}\right)$

$\mathrm{F}_{\mathrm{Ar}}$ : rate of argon flow into the molten steel $(\mathrm{Nl} / \mathrm{min})$

\section{REFERENCES}

1) S. Ban-ya, T. Shinohara, H. Tozaki and T. Fuwa: Tetsu-to-Hagané, 60 (1974), 1443.

2) K. Harashima, S. Mizoguchi, M. Matsuo and A. Kiyose: ISIJ Int., 32 (1992), 111

3) A. Kiyose, K. Harashima, K. Onuki and R. Arima: Tetsu-to-Hagané, 78 (1992), 97.

4) M. Takahashi, H. Ookuma, M. Sano, K. Mori and M. Hirasawa: Tetsu-to-Hagané, 72 (1986), 2064.

5) M. Takahashi, H. Matsuda, M. Sano and K. Mori: Tetsu-to-Hagané, 72 (1986), 419.

6) A. Thoms, S. Tu and D. Janke: Steel Res., 68 (1997), 475.

7) J. Fu, H. Chang, S. Zhou and B. Chen: J. Univ. Sci. \& Tech. Beijing, 5 (1998), 5.

8) S. Kitamura, K. Miyamoto and R. Tsujino: Tetsu-to-Hagané, 80 (1994), 101.

9) M. Numata and Y. Higuchi: ISIJ Int., 52 (2012), 2019.

10) M. Yano, K. Azuma, S. Kitamura, N. Ishiwata, K. Harashima and Y. Obana: CAMP-ISIJ, 6 (1993), 138

11) H. Katayama, H. Kajioka, M. Inatomi, F. Tanaka and H. Hosoda: Tetsu-to-Hagané, 63 (1977), 2077.

12) Z. Jian, Q. Zhe, Z. Bo, P. Q. Chun, Q. S. Tao and G. Yong: J. Iron Steel Res. Int., 20 (2013), 40.

13) Y. Xu, Z. Zhen and G. Zhang: Metall. Mater. Trans. B, 40B (2009), 345.

14) S. Kitamura, T. Inomoto, K. Okumura and K. Naito: CAMP-ISIJ, 10 (1997), 958

15) T. Inomoto, K. Harashima, M. Yano and S. Kitamura: CAMP-ISIJ, 7 (1994), 1114.

16) M. Hino and K. Ito: Termodynamic Data for Steelmaking, Tohoku University Press., Sendai, (2010).

17) Handbook of Physico-chemical Properties at High Temperatures, ISIJ, Tokyo, (1988).

18) T. Choh and M. Inoue: Tetsu-to-Hagané, 53 (1967), 1393. 